\title{
Importance of the $\beta 5-\beta 6$ Loop for the Structure, Catalytic Efficiency, and Stability of the Carbapenem-Hydrolyzing Class D $\beta$-lactamase Subfamily OXA-143
}

Víctor U. Antunes ${ }^{1}$, Edgar E. Llontop ${ }^{2}$, Fernanda N. da Costa Vasconcelos, ${ }^{3}$ Yossef López de los Santos ${ }^{4}$, Ronaldo J. Oliveira, ${ }^{5}$ Nilton Lincopan, ${ }^{6}$ Chuck S. Farah, ${ }^{2}$ Nicolas Doucet, ${ }^{4,8}$ Anthony Mittermaier, ${ }^{7,8}$ and Denize C. Favaro ${ }^{1,7 *}$

*e-mail: favarodc@unicamp.br

1 Department of Organic Chemistry, State University of Campinas, SP.

2 Department of Biochemistry, Institute of Chemistry, University of Sao Paulo, Av. Prof. Lineu Prestes 748, São Paulo, SP, 05508-000, Brazil.

3 Citrus Research and Education Center, University of Florida, FL.

4 Centre Armand-Frappier Santé Biotechnologie, Institut National de la Recherche Scientifique (INRS), Université du Québec, Laval, QC H7V 1B7, Canada.

5 Laboratório de Biofísica Teórica, Departamento de Física, Instituto de Ciências Exatas, Naturais e Educação, Universidade Federal do Triângulo Mineiro, 38064-200, Uberaba-MG, Brazil.

6 Department of Microbiology, Institute of Biomedical Sciences, University of São Paulo, São Paulo, SP 05508-900, Brazil.

7 Department of Chemistry, McGill University, QC.

8 PROTEO, the Québec Network for Research on Protein Function, Engineering, and Applications, Université Laval, QC.

Figure S1. 12\% SDS-PAGE of the purification steps of OXA-143.

Figure S2. $\mathrm{Ni}^{2+}$ affinity and size exclusion chromatograms of OXA-143.

Figure S3. UV-Vis kinetic assays of ampicillin, oxacillin, cloxacillin, flucoxacillin, ceftazidime, meropenem, doripenem and ertapenem for OXA-143, D224A and P227S in $50 \mathrm{mM} \mathrm{NaH}_{2} \mathrm{PO}_{4}$ buffer with $25 \mathrm{mM} \mathrm{NaHCO}$, pH 7.0.

Figure S4. Indirect measures of Km's by UV-Vis $(\lambda=235 \mathrm{~nm})$ for A) Meropenm, B) Doripenm and Ertapenem for (1) OXA-143, (2) D224A and (3) P227S in 50mM NaH $\mathrm{PO}_{4}$ buffer with 25 mM NaHCO, , pH 7.0. 
Figure S5. Ampicillin hydrolysis monitored by NMR spectroscopy for OXA-143, D224A and P227S.

Figure S6. Cloxacillin hydrolysis monitored by NMR spectroscopy for OXA-143, D224A and P227S.

Figure S7. Ceftazidime hydrolysis monitored by NMR spectroscopy for OXA-143, D224A and P227S.

Figure S8. Meropenem hydrolysis monitored by NMR spectroscopy for OXA-143, D224A and P227S.Figure S9. Aztreonam hydrolysis monitored by NMR spectroscopy for OXA-143, D224A and P227S.

Figure S10. Aztreonam hydrolysis by ITC: complete conversion experiment and "steps" experiments monitored by ITC.

Figure S11. A) Radius of gyration and B) RMSD of the starting minimized structure of OXA143 as a function of time using all-atom, explicit solvent MD simulations.

Figure S12. X-ray structure of D224A (PDB: 6NZ8) color-coded by RMSF differences (obtained by MD simulations) between the D224A and WT OXA-143.

Figure S13. Zoomed X-ray structure of D224A (PDB: 6NZ8) and WT (PDB: 5IY2). A indicating the electronic density for the residues M223 and Y112. The electronic density clearly indicates the presence of two conformations for M223. B expansion in the same region for the OXA-143 showing the presence of only one conformation for M223. C superposition of the two crystallographic structure pointing a more closed conformation for D224A and the two conformations for the M223 (light blue).

Table S1. Tm values of OXA-143, D224A and P227S variants in presence and absence of $\mathrm{NaHCO}_{3}$. 


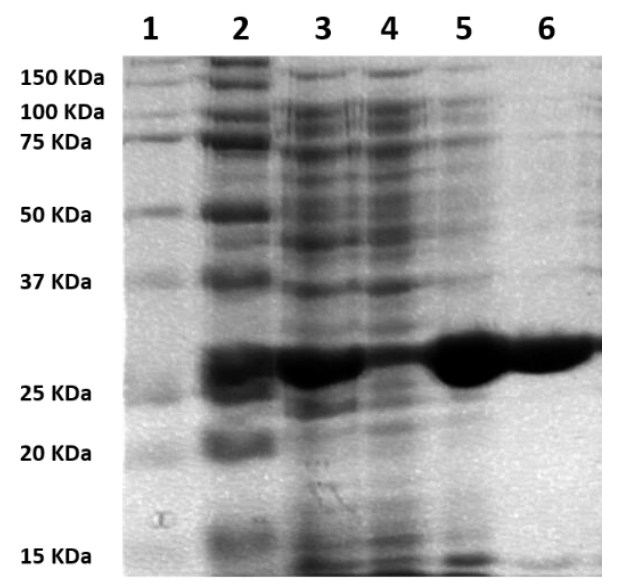

Figure S1. 12\% SDS-PAGE of the purification steps of OXA-143: molecular mass marker (lane 1); non-induced bacterial lysates (lane 2); induced bacterial lysates (lane 3); first eluted fraction from $\mathrm{Ni}^{2+}$-affinity chromatography (lane 4); eluted fraction from $\mathrm{Ni}^{2+}$-affinity chromatography containing OXA-143 (lane 5) and eluted fraction from size exclusion chromatography (lane 6).
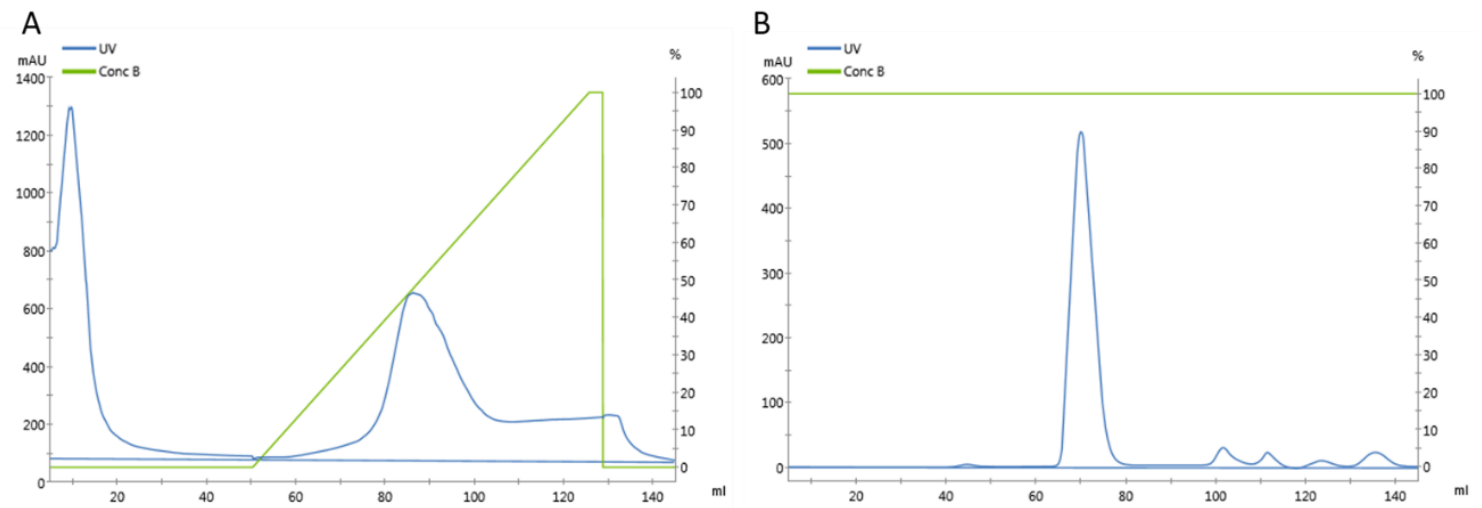

Figure S2. Ni ${ }^{2+-}$ affinity (A) and size exclusion (B) chromatograms of OXA-143. 

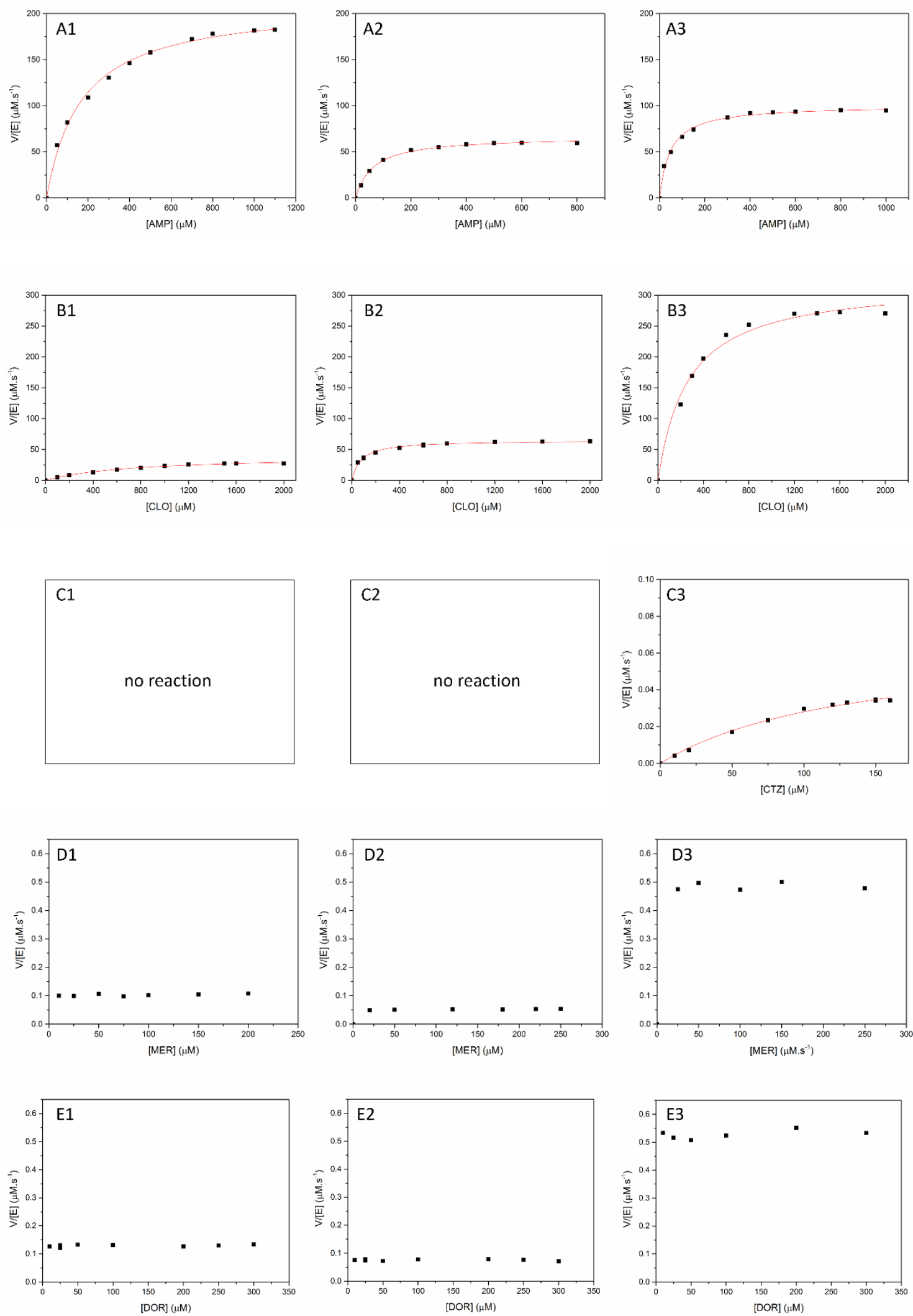

Figure S3. UV-Vis kinetic assays of A) ampicillin $(\lambda=235 \mathrm{~nm}), B$ ) oxacillin $(\lambda=263 \mathrm{~nm}), C)$ cloxacillin $(\lambda=265 \mathrm{~nm})$, D) flucloxacillin $(\lambda=263 \mathrm{~nm})$, E) ceftazidime $(\lambda=270 \mathrm{~nm}), \mathrm{F})$ meropenem $(\lambda=298 \mathrm{~nm}), \mathrm{G})$ doripenem $(\lambda=298 \mathrm{~nm})$ for (1) OXA-143, (2) D224A and (3) P227S in $50 \mathrm{mM}$ $\mathrm{NaH}_{2} \mathrm{PO}_{4}$ buffer with $25 \mathrm{mM} \mathrm{NaHCO} 3, \mathrm{pH}$ 7.0. 
A
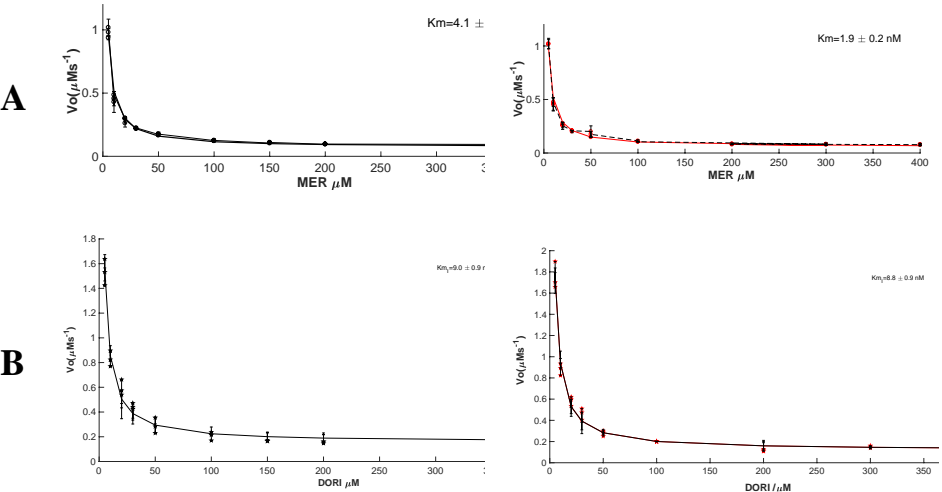

C
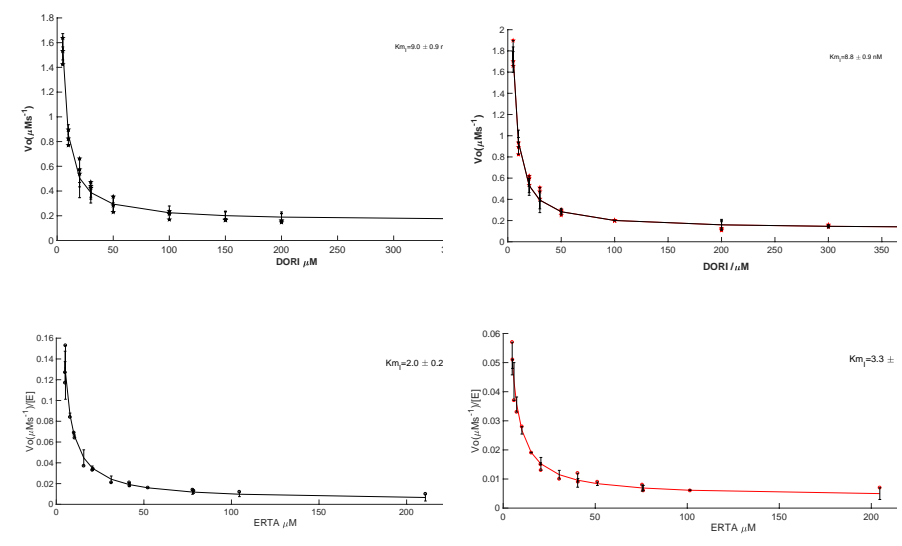
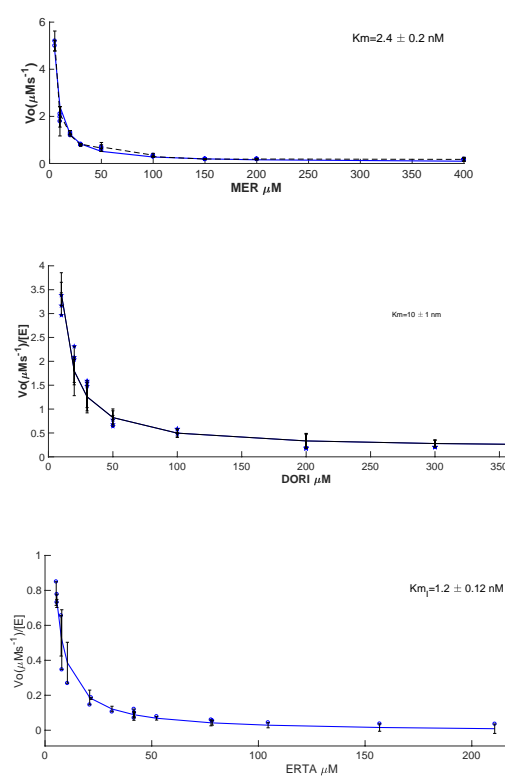

Figure S4. Indirect measures of Km's by UV-Vis $(\lambda=235 \mathrm{~nm})$ for A) Meropenem, B) Doripenem and Ertapenem for (1) OXA-143, (2) D224A and (3) P227S in $50 \mathrm{mM} \mathrm{NaH}_{2} \mathrm{PO}_{4}$ buffer with $25 \mathrm{mM}$ $\mathrm{NaHCO}_{3}, \mathrm{pH}$ 7.0.

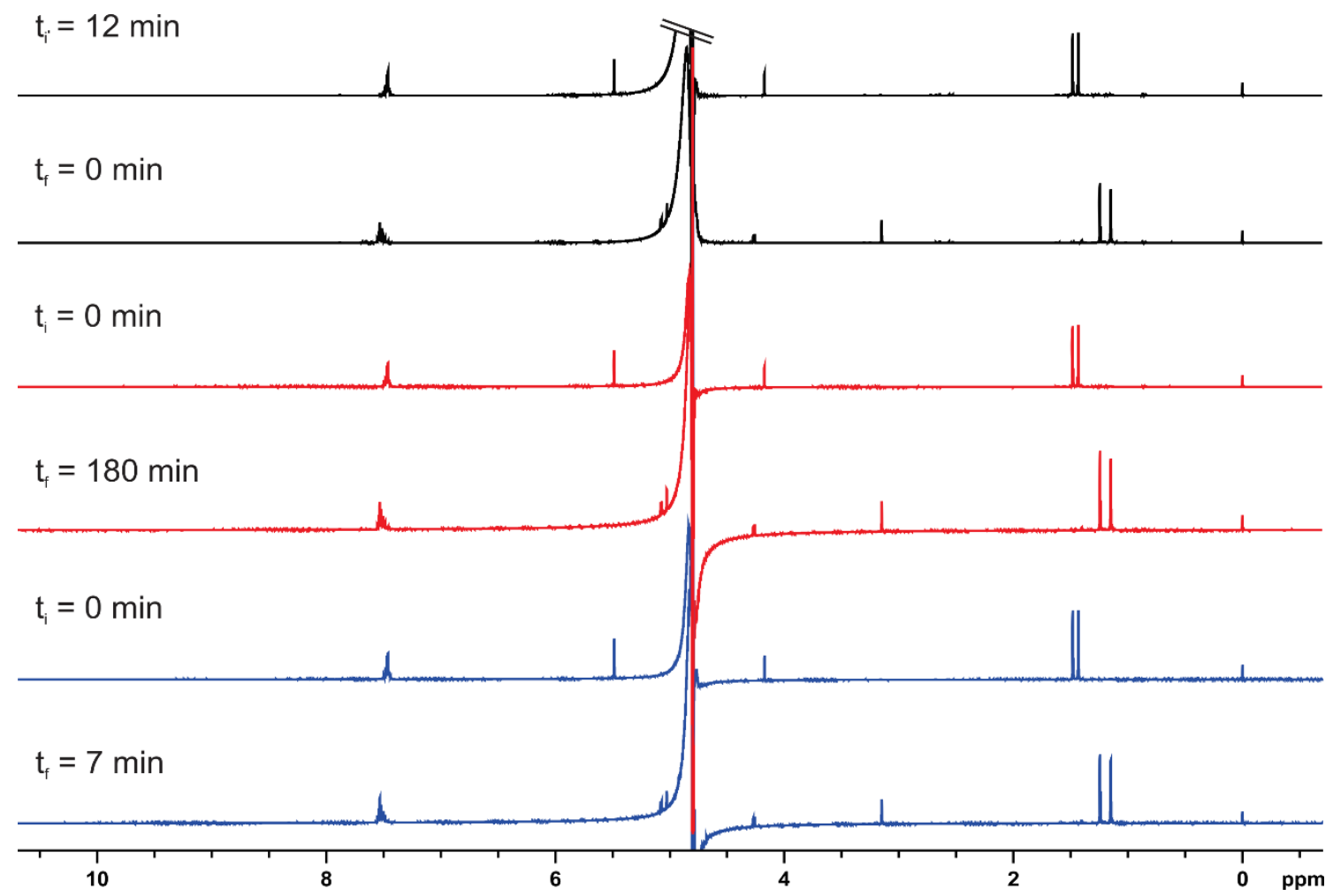

Figure S5. $5 \mathrm{mM}$ ampicillin hydrolysis monitored by NMR spectroscopy $(600.17 \mathrm{MHz}, 50 \mathrm{mM}$ $\mathrm{NaH}_{2} \mathrm{PO}_{4}, 25 \mathrm{mM} \mathrm{NaHCO} 3$ with $10 \% \mathrm{D}_{2} \mathrm{O}, \mathrm{pH} 7.0,25^{\circ} \mathrm{C}$ ) in the presence of $20 \mathrm{nM}$ OXA-143 (black), $20 \mathrm{nM}$ D224A (red) and $20 \mathrm{nM}$ P227S (blue). 


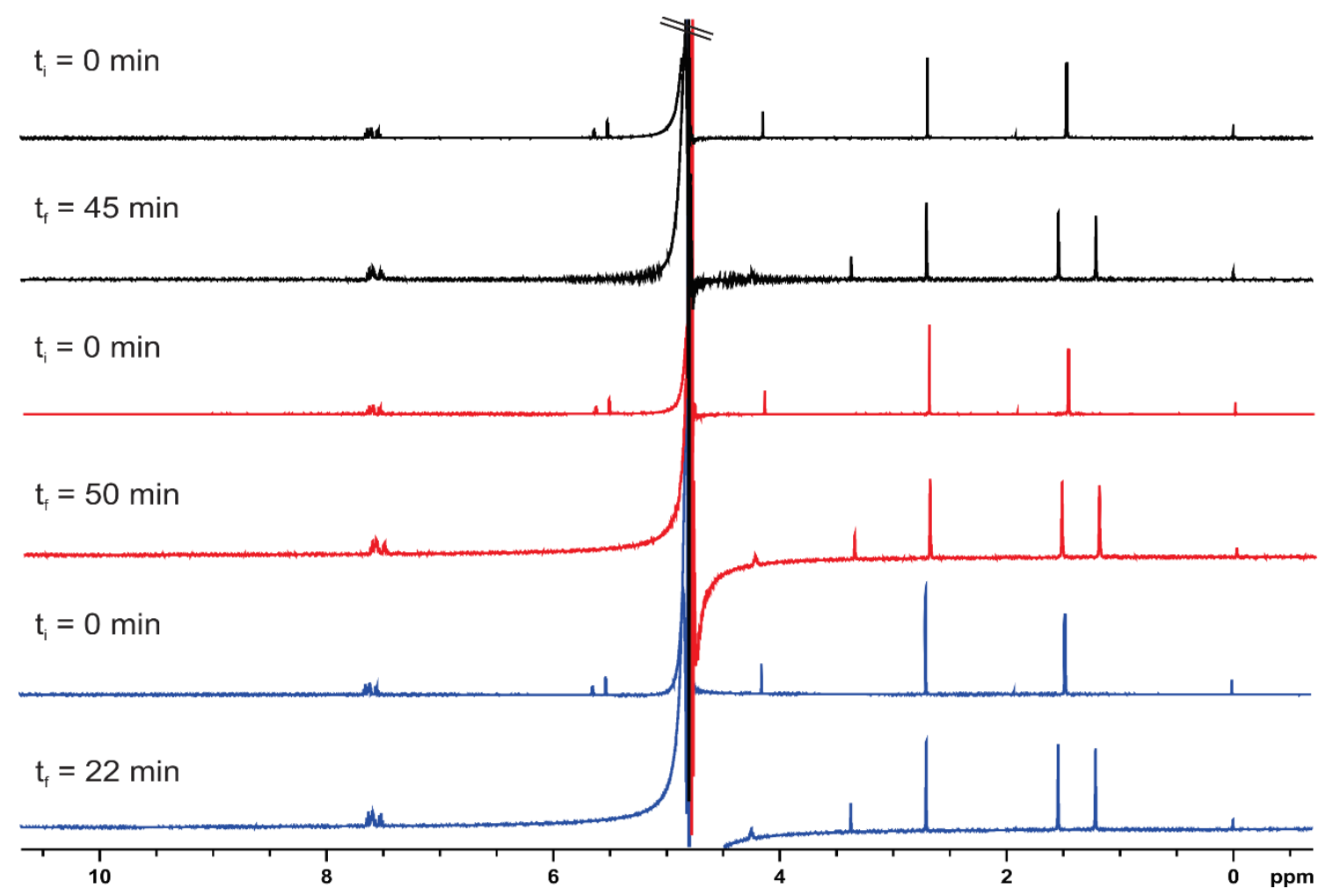

Figure S6. $2.5 \mathrm{mM}$ cloxacillin hydrolysis monitored by NMR spectroscopy $(600.17 \mathrm{MHz}, 50 \mathrm{mM}$ $\mathrm{NaH}_{2} \mathrm{PO}_{4}, 25 \mathrm{mM} \mathrm{NaHCO}$ with $10 \% \mathrm{D}_{2} \mathrm{O}, \mathrm{pH} 7.0,25^{\circ} \mathrm{C}$ ) in the presence of $40 \mathrm{nM} \mathrm{OXA}-143$ (black), $10 \mathrm{nM}$ D224A (red) and $10 \mathrm{nM}$ P227S (blue).

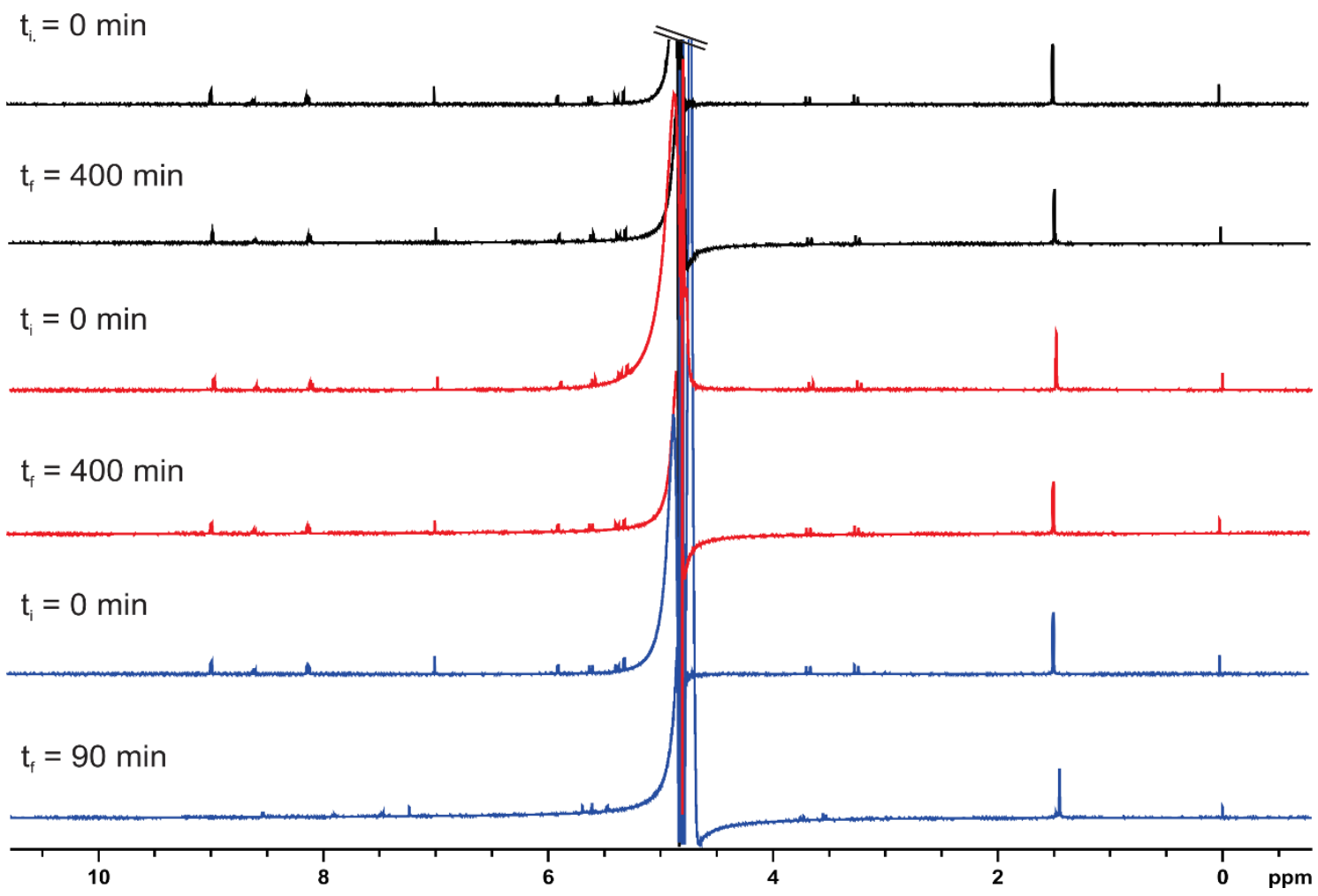

Figure S7. $1.2 \mathrm{mM}$ ceftazidime hydrolysis monitored by NMR spectroscopy $(500.18 \mathrm{MHz}, 50 \mathrm{mM}$ $\mathrm{NaH}_{2} \mathrm{PO}_{4}, 25 \mathrm{mM} \mathrm{NaHCO}{ }_{3}$ with $10 \% \mathrm{D}_{2} \mathrm{O}, \mathrm{pH} 7.0,25^{\circ} \mathrm{C}$ ) in the presence of $1.5 \mu \mathrm{M}$ of OXA-143 (black), 1.5 $\mu \mathrm{M}$ D224A (red) and 1.5 $\mu \mathrm{M}$ P227S (blue). 


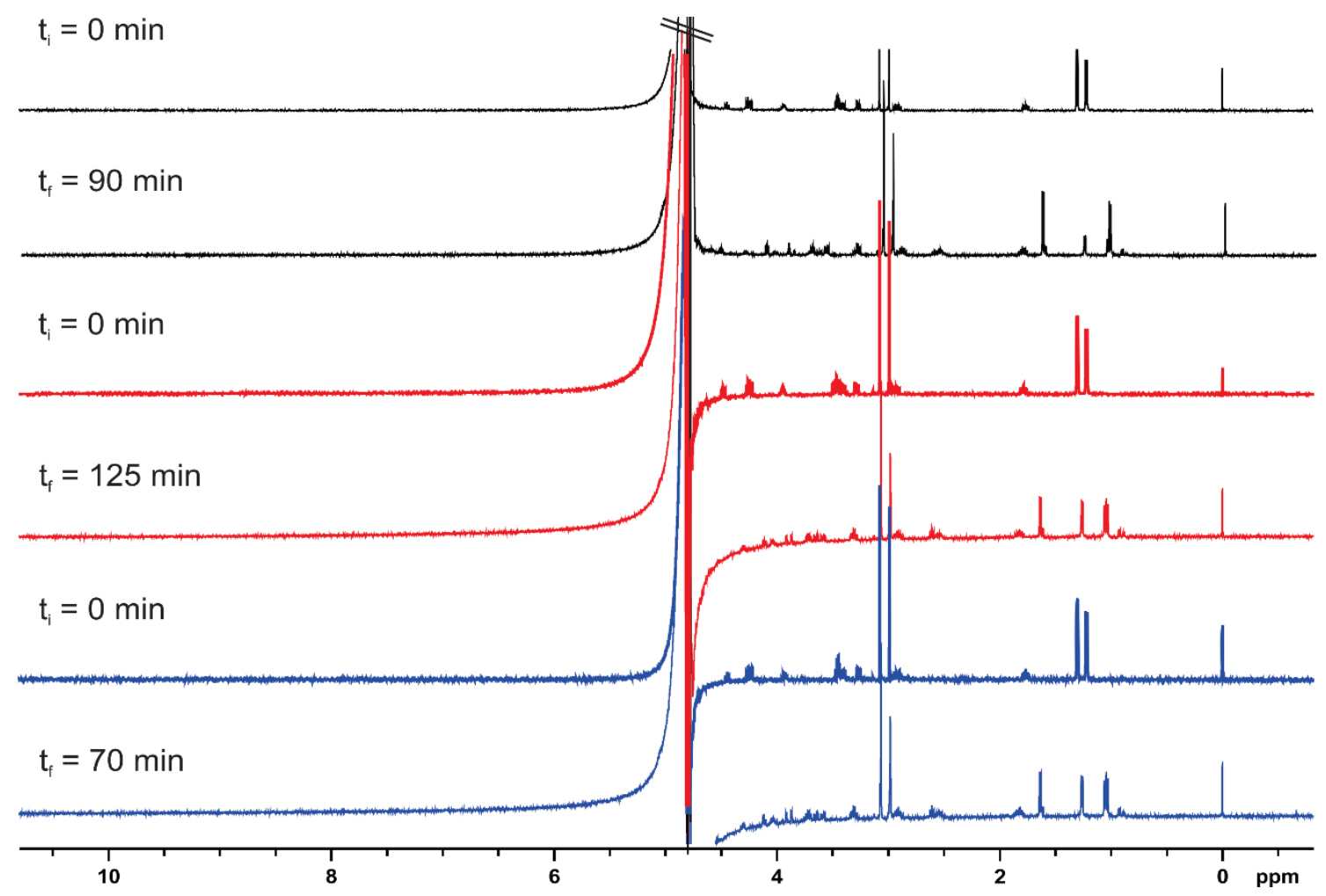

Figure S8. 1.2 mM meropenem hydrolysis monitored by NMR spectroscopy $(600.17 \mathrm{MHz}, 50 \mathrm{mM}$ $\mathrm{NaH}_{2} \mathrm{PO}_{4}, 25 \mathrm{mM} \mathrm{NaHCO} 3$ with $10 \% \mathrm{D}_{2} \mathrm{O}, \mathrm{pH} 7.0,25{ }^{\circ} \mathrm{C}$ ) in the presence of $1.5 \mu \mathrm{M}$ of OXA-143 (black), $1.5 \mu \mathrm{M}$ D224A (red) and 1.5 $\mu \mathrm{M}$ P227S (blue).

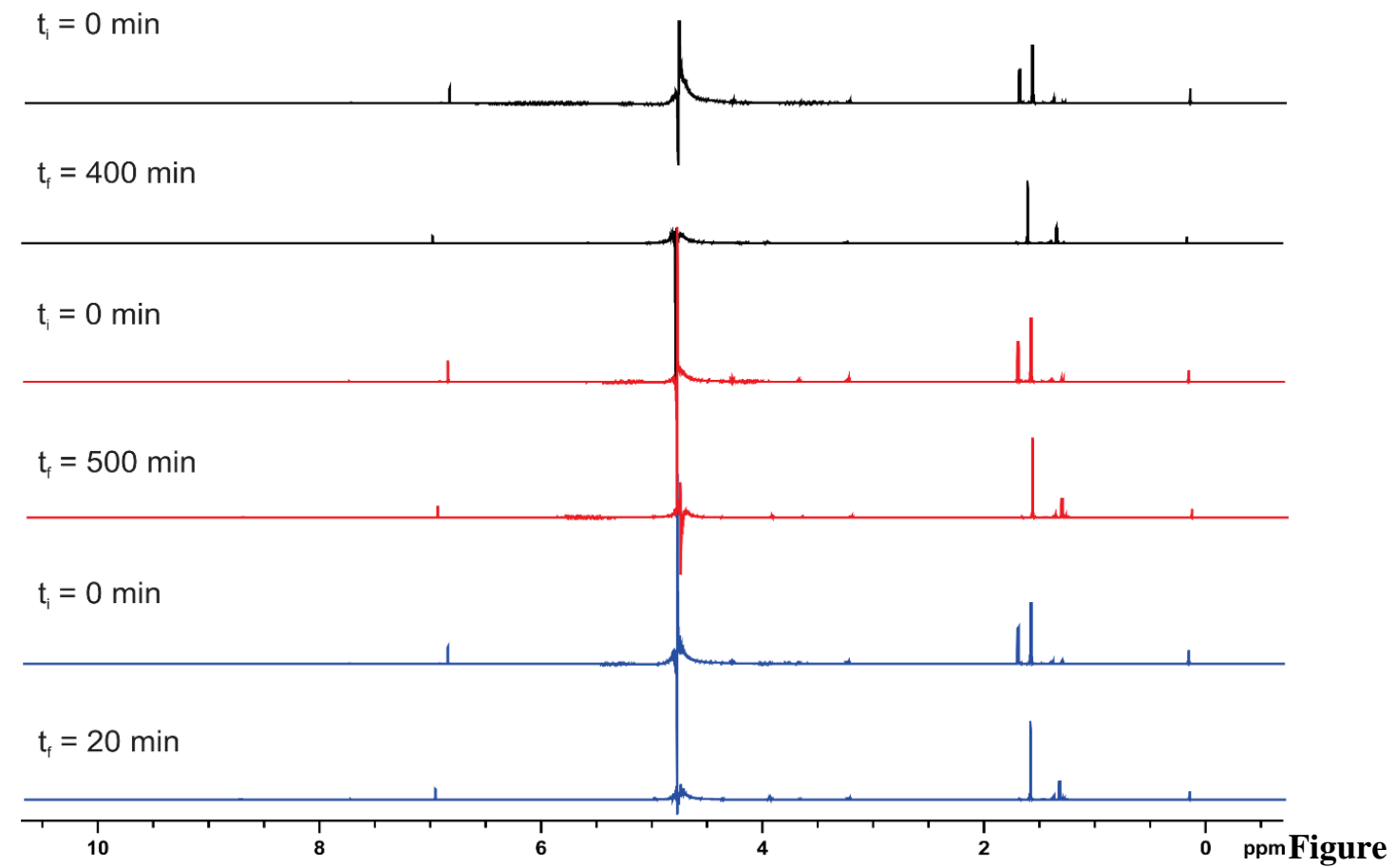

Figure S9. $1.5 \mathrm{mM}$ aztreonam hydrolysis monitored by NMR spectroscopy $(600.17 \mathrm{MHz}, 50 \mathrm{mM}$ $\mathrm{NaH}_{2} \mathrm{PO}_{4}, 25 \mathrm{mM} \mathrm{NaHCO} 3$ with $10 \% \mathrm{D}_{2} \mathrm{O}, \mathrm{pH} 7.0,25^{\circ} \mathrm{C}$ ) in the presence of $1.5 \mu \mathrm{M}$ of OXA-143 (black), $1.5 \mu \mathrm{M}$ D224A (red) and $0.4 \mu \mathrm{M}$ P227S (blue). 
A)

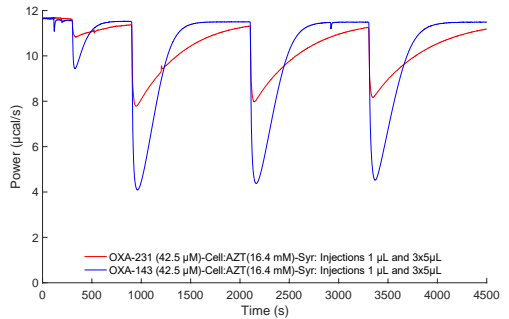

C)

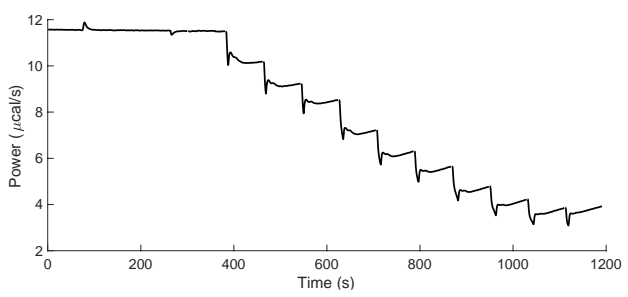

E)

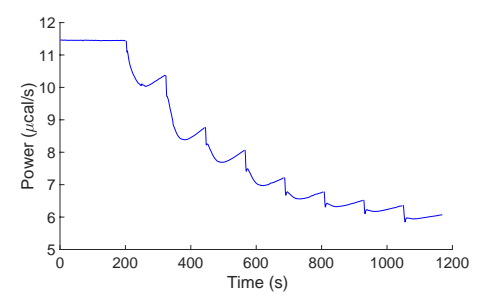

B)

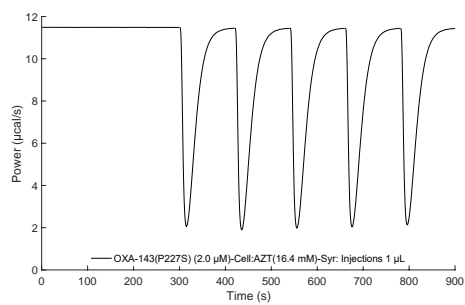

D)

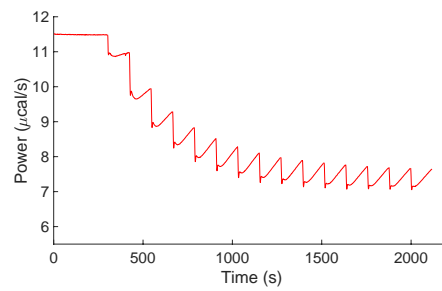

Figure S10. Complete conversion experiment using AZT $16.4 \mathrm{mM}$ in the syringe and enzyme in the cell: A) OXA-143 (42.5 $\mu \mathrm{M})$, and D224A (42.5 $\mu \mathrm{M})$; B) P227S (2 $\mu \mathrm{M})$. "Steps" experiments using $16.4 \mathrm{mM}$ AZT. C) $30 \mu \mathrm{M}$ OXA-143; D) $42.5 \mu \mathrm{M}$ D224A; E) $0.2 \mu \mathrm{M}$ $\mathrm{P} 227 \mathrm{~S}$.

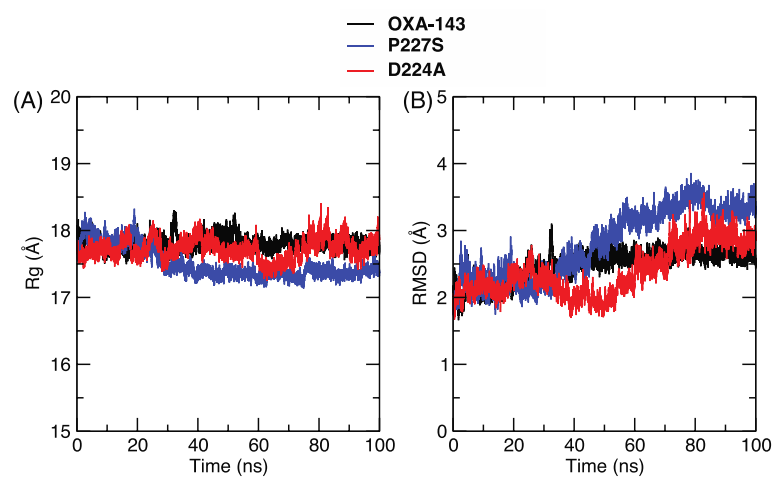

Figure S11. A) Radius of gyration ( $\mathrm{Rg}$ ) and B) root mean square deviation (RMSD) of the starting minimized structure of OXA-143 as a function of time using all-atom, explicit solvent molecular dynamics (MD) simulations. 


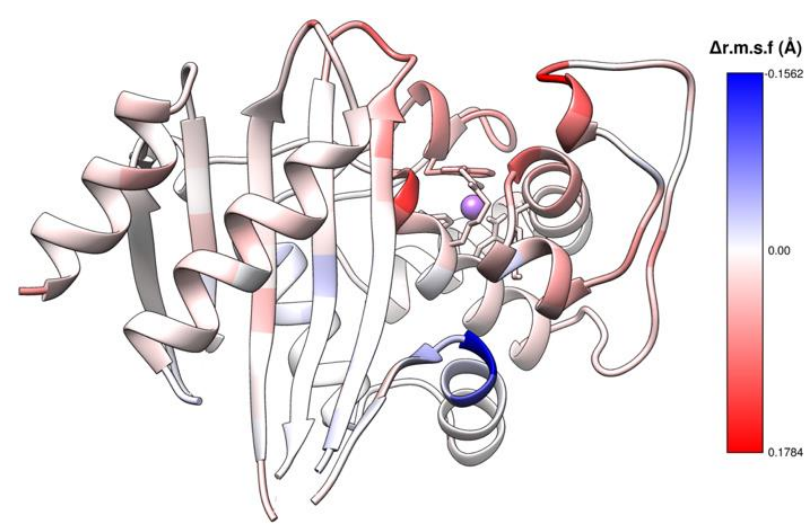

Figure S12. X-ray structure of D224A (PDB: 6NZ8) color-coded by RMSF differences (obtained by MD simulations) between the D224A and WT OXA-143.

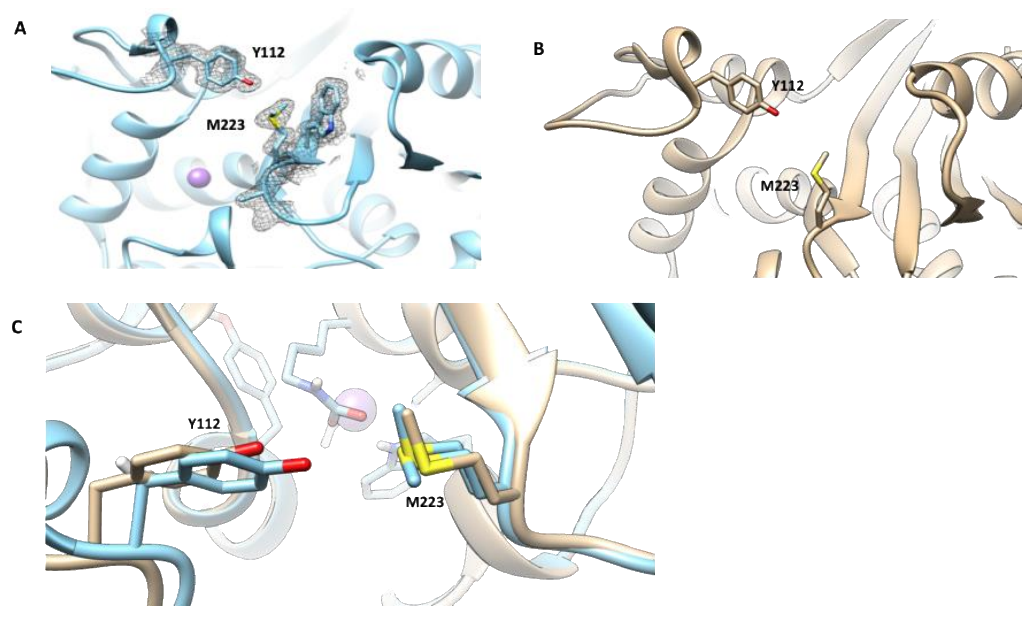

Figure S13. Zoomed X-ray structure of D224A (PDB: 6NZ8) and WT (PDB: 5IY2). A indicating the electronic density for the residues M223 and Y112. The electronic density clearly indicates the presence of two conformations for M223. B expansion in the same region for the OXA-143 showing the presence of only one conformation for M223. C superposition of the two crystallographic structure pointing a more closed conformation for D224A and the two conformations for the M223 (light blue).

Table S1. Melting temperature (Tm) for the OXA-143, D224A and P227S variants in presence and absence of bicarbonate.

\begin{tabular}{cccccc}
\hline Enzymes & $\begin{array}{c}\mathbf{T m}(\mathbf{K}) \\
\text { absence of bicarbonate }\end{array}$ & $\Delta \mathbf{T m}_{\mathbf{1}}(\mathbf{K})$ & $\begin{array}{c}\mathbf{T m}(\mathbf{K}) \\
\text { presence of bicarbonate }\end{array}$ & $\Delta \mathbf{T m}_{\mathbf{2}}(\mathbf{K})$ & $\Delta \mathbf{T m}_{3}(\mathbf{K})$ \\
\hline OXA-143 & 315 & & $323 \mathrm{~K}$ & & +8 \\
D224A & 309 & -6 & $312 \mathrm{~K}$ & -11 & +3 \\
P227S & 311 & -4 & $315 \mathrm{~K}$ & -8 & +4
\end{tabular}

$\Delta \mathrm{Tm}_{1}=\mathrm{Tm}_{\text {variant }}-\mathrm{Tm} \mathrm{wT}_{\mathrm{W}}$ in the absence of bicarbonate;

$\Delta \mathrm{Tm}_{2}=\mathrm{Tm}_{\mathrm{variant}}-\mathrm{Tm}_{\mathrm{WT}}$ in the presence of bicarbonate

$\Delta \mathrm{Tm}_{3}$ : difference between protein melting-temperatures in the presence and absence of bicarbonate.

Experiments were performed in duplicates and each value has an average uncertainty of $\pm 1 \mathrm{~K}$. 